\title{
NONLINEAR GRONWALL-BELLMAN TYPE INTEGRAL INEQUALITIES WITH MAXIMA
}

\begin{abstract}
YONG YAN
Abstract. Integral inequalities with maxima of the unknown function are useful in the study of control theory. Known results were given for Gronwall-Bellman type integral inequalities with the maxima in the form of linear dependence on the unknown function with a single delay term. In this paper we consider a general form of nonlinear integral inequalities with the maxima and more than one delay terms. Requiring neither monotonicity nor separability of given functions, we apply monotonization to estimate the unknown function. Our result can be used to weaken conditions for some known results. We apply our result to prove boundedness of solutions for a differential equation with the maxima and an integral equation with maxima separately.
\end{abstract}

Mathematics subject classification (2010): 26D10, 26D15.

Keywords and phrases: integral inequalities, maxima, estimates, boundedness.

\section{REFERENCES}

[1] T. H. GRONWALL, Note on the derivatives with respect to a parameter of the solutions of a system of differential equations, Ann. of Math. 20 (1919), 292-296.

[2] R. Bellman, The stability of solutions of linear differential equations, Duke. Math. J. 10 (1943), 643-647.

[3] D. Bainov, P. Simeonov, Integral Inequalities and Applications, Kluwer Academic, Dordrecht, 1992.

[4] D. Bainov, S. Hristova, Differential Equations Equations with Maxima, CRC Press, Francis \& Taylor, 2011.

[5] B. G. PAChPATte, Integral and Finite Difference Inequalities and Applications, North-Holland Mathematics Studies, vol. 205, Elsevier Science, Amsterdam, 2006.

[6] B. G. Pachpatte, Inequalities for Differential and Integral Equations, Academic Press, London, 1998.

[7] W. Zhang, S. Deng, Projected Gronwall-Bellman's inequality for integrable functions, Math. Comput. Modelling 34 (2001), 393-402.

[8] I. A. BIHARI, A generalization of a lemma of Bellman and its application to uniqueness problems of differential equations, Acta. Math. Acad. Hang. Sci. Hungar. 7 (1956), 81-94.

[9] O. Lipovan, A retarded Gronwall-like inequality and its applications, J. Math. Anal. Appl. 252 (2000), 389-401.

[10] R. P. Agarwal, S. Deng, W. Zhang, Generalization of a retarded Gronwall-like inequality and its applications, Appl. Math. Comput. 165 (2005), 599-612.

[11] W. S. Cheung, Q. H. MA, On certain new Gronwall-Ou-Iang type integral inequalities in two variables and their applications, J. Inequal. Appl. 8 (2005), 347-361.

[12] O. Lipovan, A retarded integral inequality and its applications, J. Math. Anal. Appl. 285 (2003), 436-443.

[13] Q. H. MA, E. H. YAng, Some new nonlinear delay integral inequalities, J. Math. Anal. Appl. 252 (2000), 864-878.

[14] F. W. Meng, W. N. Li, On some new integral inequalities and their applications, Appl. Math. Comput. 148 (2004), 381-392. 
[15] B. G. PAChPATte, On some new inequalities Related to certain inequalities in the theory of differential Equations, J. Math. Anal. Appl. 189 (1995), 128-144.

[16] L. OU-IANG, The boundedness of solutions of linear differential equations $y^{\prime \prime}+A(t) y^{\prime}=0$, Adv. Math. (China) 3 (1957), 409-418 (in Chinese).

[17] W. S. CHEUNG, Some new nonlinear inequalities and applications to boundary value problems, Nonlinear Anal. 64 (2006), 2112-2128.

[18] Y.-H. Kim, GronwalL, Bellman and Pachpatte type integral inequalities with applications, Nolinear Anal. 71 (2009), 2641-2656.

[19] W.-S. WANG, A generalized retarded Gronwall-like inequality in two variables and applications to BVP, Appl. Math. Comput. 191 (2007), 144-154.

[20] A. Golev, S. Hristova, A. RAHnev, An algorithm for approximate solving of differential equations with maxima, Comput. Math. Appl. 60 (10)(2010), 2771-2778.

[21] S. G. HRISTOVA, L. F. ROBERTS, Boundedness of the solutions of differential equations with maxima, Int. J. Appl. Math. 4, 2 (2000), 231-240.

[22] V. G. Angelov, D. D. Bainov, On the functional differential equations with maximums, Appl. Anal. 16 (1983), 187-194.

[23] E. P. Popov, Automatic Regulation and Control, Nauka, Moscow, 1966, in Russian.

[24] S. G. Hristova, K. V. Stefanova, Linear integral inequalities involving maxima of the unknown scalar functions[J], Funkcialaj Ekvacioj 53 (2010), 381-394.

[25] S. G. Hristova, K. V. Stefanova, Linear integral inequalities involving maxima of the unknown scalar functions, J. Math. Inequal. 4, 4 (2010), 523-535.

[26] J. Henderson, S. Hristova, Nonlinear integral inequalities involving maxima of unknown scalar functions, Math. Comput. Modelling 53 (2011), 871-882.

[27] M. Bohner, S. Hristova, K. Stefanova, Nonlinear Integral Inequalities Involving Maxima of the Unknown Scalar Functions, Mathematical Inequalities and Applications 12 (2012), 811-825.

[28] M. PInTo, Integral inequalities of Bihari-type and applications, Funkcialaj Ekvacioj 33 (1990), 387 403. 